\section{Commentary: Help wanted! Replicating on-the-job surgical education during the pandemic}

\author{
HelenMari Merritt-Genore, DO, ${ }^{\mathrm{a}}$ and \\ Karin Trujillo, $\mathrm{MD}^{\mathrm{b}}$
}

My former chairman would quip "well they didn't teach that in the doctor books," when referring to a particularly unique or complex situation. It is a reminder that many parts of a surgeon's development happen "on the job" and there is simply no viable substitute for that experience. Due to the pandemic, Chan and colleagues ${ }^{1}$ found themselves with limited "on-the-job" training potential for fellows in pulmonary transplantation and a need to still cultivate skills that could not be learned from medical textbooks, either. They therefore created a low-fidelity, but adaptable, model for vascular anastomosis within the thoracic cavity.

Even before the pandemic, cardiothoracic and transplant surgery fellowship have struggled to meet adequate case volumes and in turn, overall surgical experiences. A recent survey of graduating cardiothoracic surgery residents revealed that $28 \%$ "felt training inadequate" and thus pursued additional training. ${ }^{2}$ According to data from 2018, between $23 \%$ and $46 \%$ of heart and lung transplant training programs reported less than the number of cases required by United Network for Organ Sharing to qualify as a primary transplant surgeon upon graduation. ${ }^{3}$ Possibly related to this, only $38 \%$ of senior fellows actually secured a job performing transplants after graduation.

Further amplifying this issue is the heterogeneity of technical abilities that the fellow may bring to the table

From the ${ }^{\mathrm{a} N e b r a s k a}$ Methodist Health System, Methodist Physicians Clinic; and ${ }^{\mathrm{b}} \mathrm{Di}-$ vision of Cardiothoracic Surgery, Department of Surgery, University of Nebraska Medical Center, Omaha, Neb.

Disclosures: The authors reported no conflicts of interest.

The Journal policy requires editors and reviewers to disclose conflicts of interest and to decline handling or reviewing manuscripts for which they may have a conflict of interest. The editors and reviewers of this article have no conflicts of interest.

Received for publication July 31, 2021; revisions received July 31, 2021; accepted for publication Aug 3, 2021; available ahead of print Aug 17, 2021

Address for reprints: HelenMari Merritt-Genore, DO, 1120 N 103rd Plz, Omaha, NE 68114 (E-mail: helenmari.merritt@gmail.com).

JTCVS Open 2021;8:690-1

2666-2736

Copyright (c) 2021 The Author(s). Published by Elsevier Inc. on behalf of The American Association for Thoracic Surgery. This is an open access article under the CC BY-NC-ND license (http://creativecommons.org/licenses/by-nc-nd/4.0/).

https://doi.org/10.1016/j.xjon.2021.08.002

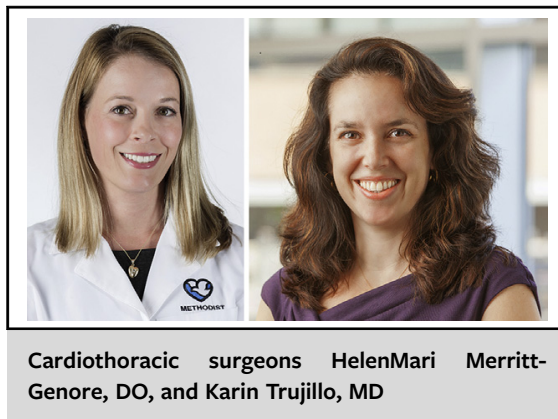

CENTRAL MESSAGE

The pandemic brought a variety of challenges to residency programs, including decreased case volumes. Simulation models may augment, but not replace, operative experiences in cardiothoracic surgery.

themselves. Data suggest these skills—at least laparoscopically-may be impacted by a surgeon's outside hobbies, like video gaming, ${ }^{4}$ and yet few opportunities exist for digital acquisition of technical skills in our field. And, although simulation and "Boot Camp" scenarios have been wellstudied, ${ }^{5}$ these opportunities were also paused due to the pandemic.

The pandemic has affected the most vulnerable first: elderly patients with comorbidities, families with economic strain, and for training programs, learners who may have already been struggling to obtain adequate case volumes or technical skills. Combined with a paucity of cases, personal protective equipment limiting participation in the operating room, and a renewed focus on efficiency and outcomes, it would be fair to assume that most learners found themselves at a disadvantage for the hands-on training so necessary to build excellent surgeons.

Obviously, simulation models are not meant to replace on-the-job training, only to augment the in-person operating experience. While simulation models may help bridge the gap as operating rooms lay quiet, we can't help but wonder if they are an appropriate or accurate means to assess the fellows' abilities and technical improvements? Likewise, do all training program have the financial and staff resources needed to implement simulation models? There are certainly data to support that simulation-based training is a reliable tool for assessing learners and for teaching skills ${ }^{4}$; however, the implementation of simulation training 
and content and fidelity of the curricula have not been uniformly employed across training programs yet.

In closing, we recognize the constraints and challenges of the anastomotic model creation and implementation, and we applauded Chan and colleagues in their efforts to maintain technical abilities through the pandemic.

\section{References}

1. Chan JCY, Waddell TK, Yasufuku K, Keshavjee S, Donahoe LL. Maintaining technical proficiency in senior surgical fellows during the COVID-19 pandemic through virtual teaching. J Thorac Cardiovasc Surg Open. 2021;8: 679-87.

2. Makdisi G, Makdisi T, Caldeira CC, Wang IW. Surgical thoracic transplant training: super fellowship_-is it super? J Surg Educ. 2018;75:1034-8.

3. Bergquist CS, Brescia AA, Watt TMF, Pienta MJ, Bolling SF. Super fellowships among cardiothoracic trainees: prevalence and motivations. Ann Thorac Surg. 2021;111:1724-9.

4. Rosser JC Jr, Lynch PJ, Cuddihy L, Gentile DA, Klonsky J, Merrell R. The impact of video games on training surgeons in the 21st century. Arch Surg. 2007;142: 181-6; discussion 186.

5. Burkhart HM, Riley JB, Hendrickson SE, Glenn GF, Lynch JJ, Arnold JJ, et al. The successful application of simulation-based training in thoracic surgery residency. $J$ Thorac Cardiovasc Surg. 2010;139:707-12. 